\title{
To Epenthesize or Not? Adaptations of English Coda [m] in Standard Mandarin Loanwords"
}

\author{
Ho-Hsin Huang, and Yen-Hwei Lin \\ Michigan State University
}

This paper examines when and why English coda [m] is or is not adapted with an epenthetic vowel in Standard Mandarin (SM) loanwords (e.g. Beckham $\rightarrow$ [pei.k ${ }^{\mathrm{h}}$ r:.han.mu:], Walmsley $\rightarrow$ [wei.mu:.sr:.li:] vs. Columbia $\rightarrow$ [kr:.lun.pi:.ja:]). A syllable coda [m] is illicit in SM; therefore, to fulfill the SM phonotactic constraints, SM speakers employ two repair strategies: vowel epenthesis after the illicit coda [m] and $[\mathrm{m}] \rightarrow[\mathrm{n}] /[\mathrm{y}]$ nasal place change. We propose an analysis based on SM speakers' perception and their native phonology to account for three cases of SM loanword adaptation of English [m]: a) when the English [m] is adapted with vowel epenthesis, b) when it is adapted with nasal place change, and c) when it is adapted variably between vowel epenthesis and nasal place change. We show that the vowel epenthesis associated with the coda [m] is conditioned by its phonological environment. The perceptual similarity experimental results from Mandarin monolingual speakers and Mandarin-English bilingual speakers suggest that the adaptation process involves speakers' perception and their native phonology.

\section{Introduction}

In loanword adaptation, when there is a mismatch between the donor and recipient languages, various repair strategies can be used to produce licit adapted forms, including epenthesis, deletion, and feature/segment change. Vowel epenthesis is a common process to satisfy phonotactic and syllable structure constraints in the recipient languages, e.g. Yoruba, Japanese, Shona, Samoan, and Sranan (Kang 2011, Kim and Kochetov 2011, Repetti 2012, Uffmann 2006, 2007). For segment preservation reasons (Paradis 1996, Paradis \& LaCharité 1997), deletion usually occurs much less frequently. Feature/segment changes commonly apply when the two corresponding segments between the donor and recipient languages differ phonologically/phonetically or occur in different phonological contexts (Kang 2011, Paradis \& LaCharité 2011, and references therein).

Nasal consonants in English have several adapted forms in Standard mandarin (SM) loanwords. The most common form is a faithful mapping in syllable onset position, e.g. Nate $\rightarrow$ [nai.t $\mathrm{t}^{\mathrm{h}} \mathrm{\gamma}$ ], Mark $\rightarrow$ [ma:. $\mathrm{k}^{\mathrm{h}} \mathrm{r}$ :]. SM allows [n] or [y] but not [m] in syllable coda position; hence, English coda [m] cannot be faithfully adapted into SM loanwords, and two repair strategies are adopted: vowel epenthesis after [m] or $[\mathrm{m}] \rightarrow[\mathrm{n}] /[\mathrm{y}]$ nasal place change. Deletion of an illicit coda [m] almost never happens, and vowel epenthesis is the default strategy, but nasal place change is adopted when $[\mathrm{m}]$ is followed by a homorganic consonant. Some examples also show variation between vowel epenthesis and nasal place change.

Based on the corpora data, we identified that the phonological environments of English coda $[\mathrm{m}]$ in the source language affect whether the epenthetic vowel appears in SM loanwords. To test the generalizations identified in the corpora and the proposed analysis, we ran perceptual similarity experiments on monolingual Mandarin speakers and bilingual Mandarin-English speakers for the adaptation process.

In the next section, we briefly review different cases of vowel epenthesis in the loanword systems of other languages. The data and the generalizations of SM vowel epenthesis are presented in $\S 3$. In $\S 4$, we propose an analysis of the three adaptation patterns of the English coda [m], vowel epenthesis, nasal place change, and variation between the epenthesis and place change. In $\S 5$, we present the perceptual similarity adaptation experiments and results from Mandarin monolingual speakers and Mandarin-English bilingual

\footnotetext{
* Special thanks go to Karthik Durvasula and Thomas Padilla, for extracting the place names from Google Maps, to Joseph Jalbert for statistics assistance, and to the Phonology-Phonetics Research Group at Michigan State University and the AMP abstract reviewers for their valuable comments and suggestions.
}

(C) 2016 Ho-Hsin Huang, and Yen-Hwei Lin

Proceedings of AMP 2015

Completed April 1, 2016 
speakers. The final section discusses the similarities and asymmetries between the corpora data and the experimental results and draws the conclusion.

\section{Vowel epenthesis in loanword adaptation}

Standard Mandarin has a very simple syllable structure. Onset and coda consonant clusters are not allowed (Duanmu 2000/2007), and only [n] or [y] can occupy the syllable coda position. Phonologically, vowel epenthesis in SM loanwords is used to avoid having [m] in coda position; however, to create a wellformed syllable, [m] deletion and nasal place change are conceivably two other possible options. In this section, we discuss vowel epenthesis in different loanword systems from phonological and phonetic/perceptual perspectives, and quality of the selected epenthetic vowel.

From the phonological perspectives, vowel epenthesis repairs an illicit syllable in the recipient language. If only well-formed syllable is at stake, coda consonant deletion and nasal place change are also possible options to fix the illicit coda [m] in SM, for example, Tom could have been adapted as $*\left[\mathrm{t}^{\mathrm{h}} \mathrm{a}\right.$ : $]$ or $*\left[\mathrm{t}^{\mathrm{h}} \mathrm{a \eta}\right]$. However, this is hardly the case. Miao's study (2005) on SM loanwords from English, German, and Italian, shows that the frequency of [m] coda deletion is low. Across the literature, it has been noted that vowel epenthesis is the most common strategy to satisfy syllable structure constraints, and the evidence from different loanword systems show that consonant deletion is not preferred crosslinguistically. Besides SM, vowel epenthesis, rather than consonant deletion, is found to be the preferred strategy to repair illicit syllables, e.g. Shinohara 1997, Katayama 1998 on Japanese, and Kenstowicz 2003 on Fijian. Paradis (1996) accounts for this asymmetry in repair strategies by the Preservation Principle (see also Rose 1995, Paradis \& Lacharité 1997), which holds that "segmental information is maximally preserved" (Paradis 1996: 511). The Preservation Principle predicts that the loan forms preserve information exists in the donor language as faithfully as possible, even at the expense of adding information. That is, in the case of SM, in order to preserve all the input information of the English coda [m] and to obey the syllable structure constraint, SM speakers add another vowel.

From the perceptual perspectives, the fact that nasal place change is not adopted often in SM loanwords may be due to the possibility that the produced outputs are less phonetically similar to the forms repaired with vowel epenthesis. Kang (2003) provides a detailed case study of vowel insertion in postvocalic word-final position in Korean loanwords from English, showing that when the native Korean phonotactic constraints are not violated, vowel epenthesis appears variably in postvocalic word-final position. She suggests that the variable adaptations can be attributed to the similarity of the perceived English input and the produced Korean loanword output. Coda consonant release in English and Korean is asymmetric: Coda consonants in English may or may not be released, whereas coda consonants are never released in Korean. Therefore, when the input is heard in two ways, Korean speakers adapt the words in two ways - with and without vowel epenthesis. When the coda consonant in English is not released, there is no vowel epenthesis in Korean loanwords, and vice versa.

Peperkamp, Vendelin \& Nakamura (2008) identify the asymmetry of word-final nasal adaptations from English and French in Japanese loanwords. English word-final codas are adapted as a moraic nasal in Japanese loanwords, e.g. pen $\rightarrow$ peN ( $\mathrm{N}=$ moraic nasal), whereas French word-final nasals are adapted with a following epenthetic vowel [u], e.g. Cannes $\rightarrow$ kann $\underline{u}$. They provide experimental evidence to explain that the asymmetry stems from the phonetic differences in the realization of word-final [n] release in English and French, and, consequently, to the way in which English and French word-final [n] are perceived by native speakers of Japanese. They further argue that loanword adaptations originate in perceptual assimilation that maps the non-native sounds and structures at the perceptual level onto the phonetically closest native ones without directly involving phonology.

Other than the question of whether vowel epenthesis applies for phonological or perceptual reasons, which vowel is inserted in the given language is another question. Uffmann (2007) categorizes vowel epenthesis in different loanword systems into three groups: default segments, vocalic spreading, and consonant assimilation. The default epenthetic vowel is language specific and it is the phonetically shortest and perceptually most confusable vowel (Steriade 2008) in the language. For example, the default epenthetic vowel in Japanese loanwords is [u] (Park 1986, Shinohara 1997, Katayama 1998); in English there is sometimes a schwa observed in consonant clusters, e.g. Arm [a. $\left.{ }^{\circ} \mathrm{m}\right]$ (Hall 2006). Kenstowicz (2003) 
also claims that the default epenthetic vowel in Fijian loanwords is the phonetically shortest [i]. Phonologically, the default epenthetic vowel is the least specified vowel according to the underspecification theory (Archangeli 1988, Itô \& Padgett 1995, Pullyblank 1988 on Yuroba, Abaglo \& Archangeli 1989 on Ganbe).

It is also observed that the epenthetic vowel can be copied from the preceding or following vowel, e.g. the epenthetic vowel in Sranan is the same as the one that exists in the word (Uffmann 2007). Paradis (1996) also finds that in Fula, the epenthetic vowel is determined by the nearest vowel or vocoid in the word.

Different from vowel copying and the default epenthetic vowel in a language, the epenthetic vowel $[\mathrm{u}] /[\mathrm{o}]$ after $[\mathrm{m}]$ in SM loanword from English falls into the consonant assimilation realm. The epenthetic vowel shares the labial feature with the preceding [m]. This type of assimilation process is common in loanword systems crosslinguistically. Hyman (1970) shows that $[\mathrm{u}]$ is inserted in labial contexts in Nupe. Smith (1977) shows that the default epenthetic vowel in Haya is [i], however, [u] takes place in the labial environments.

Vowel epenthesis in SM loanwords can be explained by the need to satisfy syllable structure constraints; however, to fix an illicit syllable with a coda [m], nasal place change and deletion are two other possible strategies. For syllable repairs, SM speakers tend to preserve all the segments from the donor language, English, hence deletion almost never occurs. Besides the phonological reasons, we propose that the perception of the fine acoustic cue plays a role in the adaptation process. The quality of the epenthetic vowel is derived from consonant assimilation, i.e. the labial feature of [m] spreads to the epenthesized vowel. The following section presents the vowel epenthesis and nasal place change data in SM loanwords and identifies the generalizations.

\section{SM loanword data and generalizations}

Two different corpora were used in this study. One comes from Appendix I, a list of British and American names, of a New English-Chinese Dictionary (1988), and the other contains major American city names with English to Chinese transliterated forms from Google Maps (Google Maps, 2015). The dictionary corpus has around 2400 British and American male and female names. The Google Maps corpus consists of around 2000 major city and state/province names of the United States and Canada. We also collected some data from public media, e.g. movies, newspapers, and magazines. More than 2000 [m] in different syllable positions were examined.

By looking only at English coda [m], the main data from the corpora can be grouped into three types: (i) adapted forms with nasal place changes in SM loanwords, $[\mathrm{m}] \rightarrow[\mathrm{n}] /[\mathrm{n}]$, (ii) those with vowel epenthesis, [m] $\rightarrow$ [mu], and (iii) those that are variably adapted between nasal place change and vowel epenthesis. Each type occurs consistently under specific phonological environments.

Vowel epenthesis appears in SM loanwords when the English coda [m] is in word-final and wordmedial non-homorganic environments. The examples in (1) illustrate that the [m] in word-final or wordmedial coda position in both monosyllabic and disyllabic words is adapted with vowel epenthesis.

(1) English $\rightarrow \quad$ SM

a. [m] in word-final coda position in monosyllabic words

Jim [tci..mu:]

Kim [tci..mu:] [tcin.mu:]

Sam [san.mu:]

Tim $\quad$ [ti..mu:

Tom $\quad\left[\mathrm{t}^{\mathrm{h}}\right.$ ay.mu: $]$

Rum [lay.

b. $[\mathrm{m}]$ in word-final coda position in disyllabic words
Abram
[a:.pu:.la:.mu:]

Beckham

[pei.k ${ }^{\mathrm{h}}$ r:.han.mu:] 


\begin{tabular}{|c|c|}
\hline Beerbohm & [pi:.əı.p" ${ }^{\mathrm{w}}$ o:.mu: \\
\hline Hingham & [6in.ə:.mu:] \\
\hline Salem & [sa:.lv:.mu:] \\
\hline
\end{tabular}

c. [m] in word-medial coda position in disyllabic words

\begin{tabular}{|c|c|}
\hline Armstrong & [a:.mu:.și:tşuay] \\
\hline Beamsville & [pi:.mui.st..wei.ər] \\
\hline Camlin & 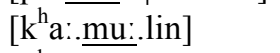 \\
\hline Camrose & {$\left[\mathrm{k}^{\mathrm{h}} \mathrm{a}: \overline{\mathrm{mu}}: \mathrm{I}^{\mathrm{w}}{ }_{0}: . \mathrm{SI}\right]$} \\
\hline Plimsoll & [p ${ }^{\mathrm{h}} \mathrm{i} . . \mathrm{li} . \mathrm{mu} . \mathrm{s}^{\mathrm{w}} \mathrm{o}$ o:. \\
\hline
\end{tabular}

The examples in (2) show that in either word-medial or word-final coda position, vowel epenthesis does not apply when $[\mathrm{m}]$ is followed by a homorganic obstruent.

(2) English $\rightarrow \quad \mathrm{SM}$

a. $[\mathrm{m}]$ in word-medial homorganic contexts $[\mathrm{b} / \mathrm{p} / \mathrm{f}]$

\begin{tabular}{|c|c|}
\hline Amboy & [an.pp $\left.{ }^{\mathrm{w}} \mathrm{o:.ji}:\right]$ \\
\hline Columbia & [ke.lun.pi:.ja:] \\
\hline Humphrey & [han.fu:.lai] \\
\hline Olympia & [ao.lin.phi:.ja:] \\
\hline Pampers & [pan.pao.s.I] \\
\hline Tempa & [t $\mathrm{t}^{\mathrm{h}}$ an.pa: $]$ \\
\hline
\end{tabular}

b. $[\mathrm{m}]$ in word-final homorganic contexts $[\mathrm{p} / \mathrm{f}]$

$\begin{array}{ll}\text { Camp } & {\left[\mathrm{k}^{\mathrm{h}} \text { an.pu: }{ }^{\mathrm{pu}}\right]} \\ \text { Tempe } & {\left[\mathrm{t}^{\mathrm{h}} \text { an. } \mathrm{p}^{\mathrm{h}} \mathrm{ei}\right]} \\ \text { Triumph } & \text { [tai.an.fon] }\end{array}$

However, the examples in (3) show that when the pre-[m] vowel in English is a long vowel or a diphthong, vowel epenthesis still applies even though $[\mathrm{m}]$ is followed by a homorganic obstruent. ${ }^{1}$

\begin{tabular}{|c|c|c|}
\hline 3) English & $\rightarrow$ & SM \\
\hline Bloomfield & & [pu:.lu:.mu:.fei.əs.tr:] \\
\hline Shaumberg & & [sau.mu:.pau] \\
\hline
\end{tabular}

As the examples in (4) show, variation occurs when English coda [m] is followed by a non-labial stop: $[\mathrm{m}]$ can be adapted with or without vowel epenthesis in SM loanwords.

(4) English $\rightarrow \quad$ SM

Binghamton [pin.han.mus.tun] [pin.han.tun]

Camden $\quad\left[\mathrm{k}^{\mathrm{h}} \mathrm{a}:\right.$.mu.t.təy $] \sim\left[\mathrm{k}^{\mathrm{h}}\right.$ ən.

Hamden [han.mu:tun] [han.tun]

Palmdale $\quad\left[\mathrm{p}^{\mathrm{h}}\right.$ a:.mu:.tai.əx $] \sim\left[\mathrm{p}^{\mathrm{h}}\right.$ an.tai.əx $]$

Sumter [say:..mu:.tr:] [san.tr:]

In the corpora, there are 355 cases of [m] in coda position. When English coda [m] is in word-medial and word-final non-homorganic contexts, the vowel epenthesis rate in SM loanwords is about $80 \%$. Vowel epenthesis never occurs in SM loanwords when the coda $[\mathrm{m}]$ in English is in a homorganic environment and preceded by a lax vowel. Table 1 shows the counts and percentages of the appearance of vowel epenthesis in different phonological environments.

\footnotetext{
${ }^{1} \mathrm{We}$ found only 2 cases with this pattern.
} 


\begin{tabular}{c|cc}
\hline Phonological environments & Counts & Percentages \\
\hline Word-final & $80 / 100$ & $80 \%$ \\
Word-medial & $130 / 167$ & $77 \%$ \\
Homorganic (prenasal vowel lax) & $0 / 86$ & $0 \%$ \\
Homorganic (prenasal vowel long) & $2 / 2$ & $100 \%$ \\
Total & $212 / 355$ & $60 \%$ \\
\hline
\end{tabular}

Table 1. The counts and percentages of English coda [m] triggering vowel epenthesis in SM loanwords.

In addition, we also found that when $[\mathrm{m}]$ in English is ambisyllabic ${ }^{2}$ or in word final position ${ }^{3}$, nasal insertion occurs, e.g. Sammy $\rightarrow$ [san.mi:], sauna $\rightarrow$ [san.na:], Sam $\rightarrow$ [san.mu:] and the place of the inserted nasal, in most cases, agrees in backness with its preceding vowel in English (cf. Hsieh, Kenstowicz \& Mou 2009). Moreover, the epenthetic vowels are all [+round], [u] in most cases, and [o] in only two words (cf. Uffmann 2006 on epenthetic vowel quality through consonant assimilation).

In the next section, we provide an account of the adaptation patterns of English coda [m] in SM loanwords from phonological and phonetic perspectives

\section{Phonological and phonetic explanations}

As mentioned earlier in $\S 2$, SM does not allow complex onsets and codas, and the only consonants that can appear in syllable coda position are [n] and [n]. Therefore, vowel epenthesis after [m] in SM loanwords is motivated by SM phonology to fix the illicit [m] in coda position. In addition, we suggest that vowel epenthesis has the advantage of fully retaining the features of the labial consonant and hence improves the similarity between the English inputs and the SM loanword outputs.

Among the three possible repair strategies, deletion, vowel epenthesis and nasal place change, deletion is not chosen to repair the syllable due to the need for segment preservation (Paradis 1996, Paradis \& LaCharite 1997). The segment information is maximally preserved, even at the expense of adding a vowel, since resyllabifying the coda [m] to the onset position of the epenthetic vowel in SM loanwords not only preserves the manner feature but also the place feature of $[\mathrm{m}]$ in English. We also suggest that perceptually vowel epenthesis after [m] could help match any perceived consonant release (cf. Kang 2003, Peperkamp, Vendelin \& Nakamura 2008) in word-medial and word-final positions. Based on both phonological and perceptual reasons, vowel epenthesis is favored over nasal place change as the main repair strategy.

When $[\mathrm{m}]$ is followed by a labial consonant, i.e. in a homorganic environment and preceded by a lax vowel in English, vowel epenthesis never appears in the existing SM loanword corpora. In English, a stopobstruent sequence is produced with a gestural overlap (e.g. [m.p]/[m.b]/[m.f $]$ ), such that there is weak or no audible release for the first stop (Henderson \& Repp 1982, Browman \& Goldstein 1990). Hence, vowel epenthesis never occurs in such homorganic environments.

It is interesting to note that prenasal vowel quality seems to affect the occurrence of vowel epenthesis after $[\mathrm{m}]$ in SM loanwords. When the pre-[m] vowel is long or a diphthong in English, epenthesis still occurs, even when $[\mathrm{m}]$ is under the homorganic condition, e.g. English [CVVmpV] $\rightarrow$ SM [CVV.mui..pV] We propose that SM speakers prefer to match the vowel duration as the priority to fulfill the $\mu \mu$-syllable constraint (Duanmu 2000/2007, Lin 2007) and resyllabify the English coda [m] with an epenthetic vowel. In these cases, vowel epenthesis fixes the illicit consonant sequences such as [mp] in SM.

We propose that variable adaptations occur as a result of the weak release or no audible release after the coda consonant in stop sequences. Coda consonants may or may not be released (cf. Kang's variable adaptation forms in Korean loanwords), or depending on the following consonant (Malécot 1958, Selkirk 1982, Crystal \& House 1988) have various degree of release in English (Davidson 2011). Hence, speakers are indeterminate with the release cue. We suggest that when the input is perceived with different degrees of consonant release, the SM loanwords are produced in two ways-with and/or without vowel epenthesis

\footnotetext{
${ }^{2}$ The $[\mathrm{m}]$ is defined as an ambisyllabic consonant when the vowel before [m] is non-high, lax and bears the primary word stress.

${ }^{3}$ For the cases where English coda $[\mathrm{m}]$ is in word final position, the loan forms undergo nasal insertion and vowel epenthesis processes. More examples can be found in (1) a.
} 
(i.e. nasal place change).

The next section presents the perceptual experiments run on Mandarin monolingual speakers and Mandarin-English bilingual speakers to test whether perceptual factors play a role and to see whether the patterns found in the experimental results match the generalizations identified in the corpora.

\section{Perceptual experiment and results}

To test the extent to which the generalizations identified in the corpora are based on perceptual repairs, a nonce word perceptual similarity adaptation task was run on Mandarin-English bilingual and monolingual Mandarin speakers. The main goals of the experiment are (i) to examine the validity of the generalizations identified in the corpora, and (ii) to examine whether perceptual similarity plays a crucial role in loanword adaptation, i.e. whether the SM speakers perceive fine phonetic cues, as proposed above, when they borrow words from English.

5.1 Hypothesis, design, procedure, and materials Our hypothesis is that the outputs of SM loanwords are judged by SM speakers perceptually more similar to their English inputs. Since our corpora are drawn from an English-Chinese dictionary and Google Maps, we assume that the people who generated or created the data in the corpora are bilingual speakers of Mandarin and English. Hence, we recruited 24 Mandarin-English bilingual speakers at Michigan State University. By the experiment time, they had lived in the United States for more than three years. They were either graduate teaching assistants at Michigan State University or employees of local companies. They all have to speak English at work or regularly in their daily life. For comparison, we also ran the same experiment on 33 monolingual Mandarin speakers. They were college students at National Chengchi University in Taiwan with little chance to speak English. By the experiment time, they had never lived in any English speaking country and they did not speak any other Chinese dialects.

The English test items were recorded by a female American English speaker from the Chicago area. A high quality microphone, Blue Yeti Pro, was connected to a MacBook Air to capture the sounds. The test items were recorded and normalized to $70 \mathrm{~dB}$ on Praat (Boersma \& Weenink 2016) in a soundproof room of the Linguistics Department at Michigan State University. The possible outputs in SM were recorded by a female Chinese instructor at Michigan State University from Taiwan with the same recording equipment, in the same room, and were normalized to the same intensity as the English test items.

There were 40 nonce word test items and 90 filler items. (See the Appendix for the full list of the test items.) The test items had a [m] in (a) word-final coda position, (b) word-medial (non-homorganic) coda position, or (c) word-medial homorganic coda position, with both prenasal tense/diphthong and lax vowels. The prenasal vowels in the test items were [i, I, e, $\varepsilon, \mathfrak{x}, \mathrm{u}, \mho, \mathrm{o}, \mathrm{\jmath}, \mathrm{a}, \mathrm{a} v]$. The two possible SM outputs were those with and without vowel epenthesis, e.g. [lin] and [li:mu:]. Since almost all the epenthetic vowels $(99.9 \%)$ found in the corpora were [u], only two [o] cases, we used [u] in all the possible SM outputs. The recordings were embedded into Psychopy (Peirce 2009) and the experiment was run on it as well.

All the instructions were given on Psychopy in Mandarin. Before the experiment started, there was a practice session with ten questions that were similar to the test questions. In both practice and test sessions, the participants listened to two possible SM adapted forms followed by an English input, and chose the one that is the more perceptually similar SM adapted form to the English input. For example, the participants listened to two possible Mandarin outputs, one with nasal place change and the other with vowel epenthesis, e.g. [lin] and [li:.mu:], followed by the English input, [lim]. The inter-stimulus interval between each sound was $500 \mathrm{~ms}$. After they listened to all three sounds, they saw "A or B" on the screen. The first SM sound they listened to was A and the second one was B, and they used the right or left arrow key on the keyboard to make the selection. The left arrow key corresponds to A; the right arrow key corresponds to B. The experiment took about 35-40 minutes. All the participants received 15 USD for their time and participation.

5.2 Results from the bilingual speakers Table 2 compares the bilingual vowel epenthesis rate and the corpora vowel epenthesis rate in percentages when English coda $[\mathrm{m}]$ is in different phonological environments. 


\begin{tabular}{c|cc}
\hline Phonological environments & $\begin{array}{c}\text { Vowel epenthesis from } \\
\text { bilingual experimental results }\end{array}$ & Vowel epenthesis in the corpora \\
\hline Word-final & $68 \%$ & $80 \%$ \\
Word-medial & $64 \%$ & $77 \%$ \\
Homorganic (prenasal vowel lax) & $38 \%$ & $0 \%$ \\
Homorganic (prenasal vowel long) & $19 \%$ & $100 \%$ \\
\hline
\end{tabular}

Table 2. The comparison of vowel epenthesis rate in percentages of the bilingual experimental results and the corpora data.

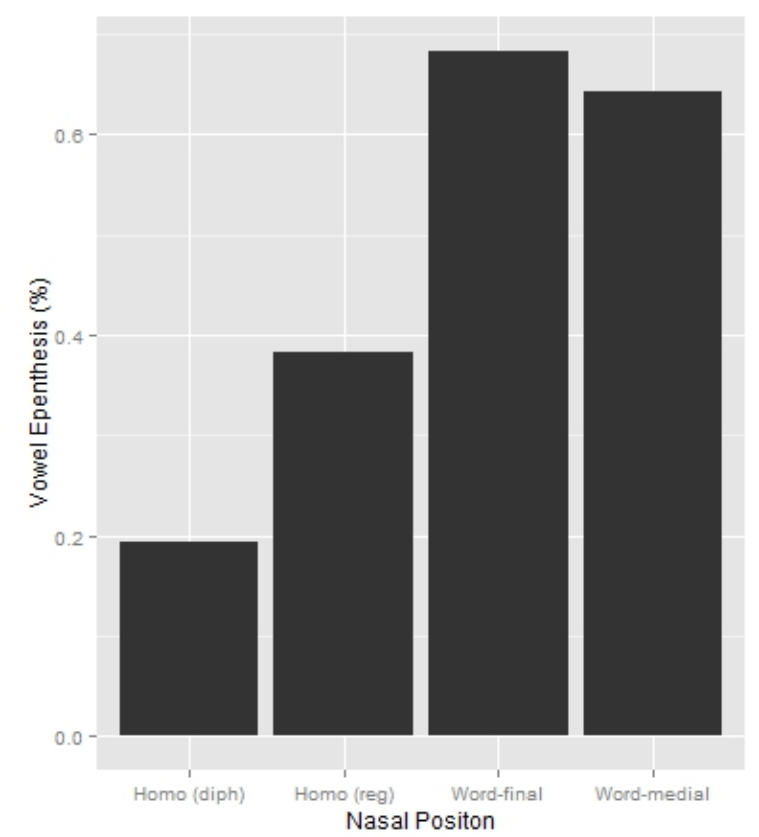

Figure 1. Bilingual experimental results of vowel epenthesis rate of English coda [m] in different phonological environments.

Figure 1 shows vowel epenthesis rate of bilingual results when English coda [m] is in word-medial and word-final positions and homorganic environments. We ran t-tests to compare the preference of bilingual speakers for vowel epenthesis separately for homorganic environments vs. non-homorganic environments. T-tests reveal that the vowel epenthesis preference is significantly higher in the non-homorganic group than in the homorganic group $[\mathrm{t}(23)=7.53, \mathrm{p}<0.001]$. The preference for vowel epenthesis rate in SM between English word-medial and word-final coda is not significantly different $[t(23)=1.062, p=0.299]$.

The bilingual speakers follow the generalizations in the corpora data in using vowel epenthesis as the preferred repair strategy to fix the illicit word-medial and word-final coda [m] in English. In general, the experimental results show that nasal place change is the preferred repair strategy in homorganic environments. Furthermore, in the corpora data, there were no cases of vowel epenthesis for the homorganic condition with a lax vowel, whereas every case of the homorganic condition with a long vowel had vowel epenthesis. The experimental results show higher preference $[\mathrm{t}(23)=3.26, \mathrm{p}<0.05]$ for vowel epenthesis in the homorganic condition with a lax vowel than in the homorganic one with a long vowel, although unlike the corpora data, nasal place change is generally preferred for both types of homorganic conditions.

5.2 Results from the monolingual speakers Table 3 and Figure 3 present the monolingual speakers' vowel epenthesis rate in percentages when English coda [m] is in different phonological environments. 


\begin{tabular}{c|c}
\hline Phonological environments & $\begin{array}{c}\text { Vowel epenthesis from } \\
\text { monolingual experimental results }\end{array}$ \\
\hline Word-final & $49 \%$ \\
Word-medial & $51 \%$ \\
Homorganic (prenasal vowel lax) & $29 \%$ \\
Homorganic (prenasal vowel long) & $24 \%$ \\
\hline
\end{tabular}

Table 3. Vowel epenthesis rate in percentages of the monolingual experimental results.

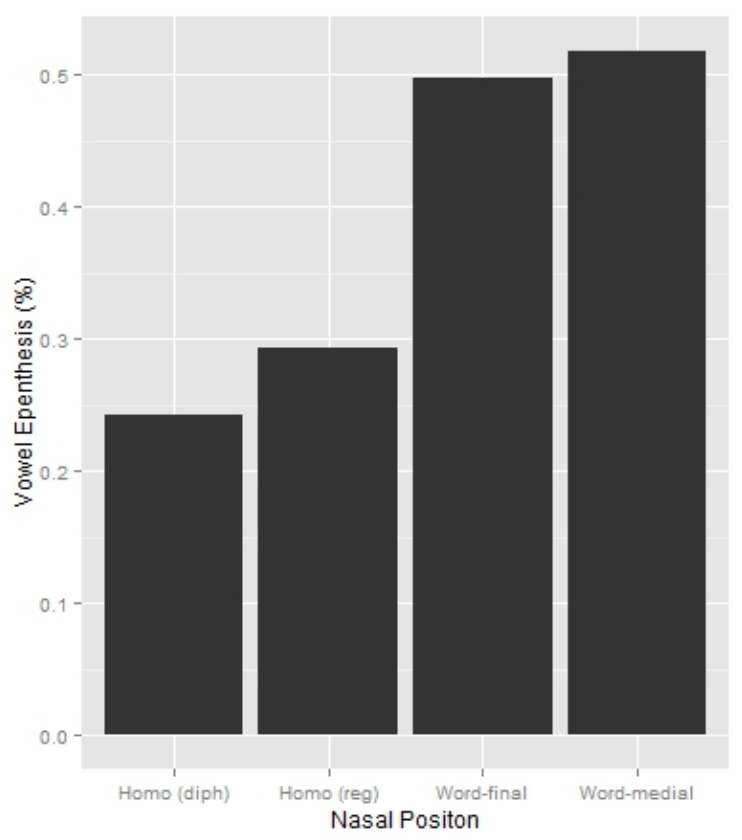

Figure 3. Monolingual experimental results of vowel epenthesis rate of English coda [m] in different phonological environments.

We ran t-tests to compare the preference of monolingual speakers for vowel epenthesis separately for homorganic environments vs. non-homorganic environments. T-tests reveal that the preference for vowel epenthesis is significantly higher in the non-homorganic group than in the homorganic group $[\mathrm{t}(32)=5.65$, $\mathrm{p}<0.001]$. The vowel epenthesis rate in SM between English word-medial and word-final coda is not significantly different $[\mathrm{t}(32)=1.06, \mathrm{p}=0.55]$. If we looked at the monolingual results more closely, we can see that the monolingual speakers differ from bilingual speakers in that they do not strongly prefer epenthesis as the syllable repair strategy when [m] is in word-medial and word-final position in English. In general, the experimental results show that nasal place change is the preferred repair strategy in homorganic environments. Unlike the bilingual results, the monolingual results do not show significant difference $[\mathrm{t}(32)=1.10, \mathrm{p}=0.277]$ in vowel epenthesis between the homorganic condition with a lax vowel and the homorganic one with a long vowel.

5.3 Summary A comparison of the vowel epenthesis rates among the corpora and the bilingual/monolingual experimental results is given in Table 4 . Overall, both homorganic conditions disfavor vowel epenthesis in the experimental results. Since only two examples were found in the corpora for the homorganic condition with a prenasal long vowel, the results suggest that a sequence of $[\mathrm{m}]$ followed by a homorganic consonant inhibit vowel epenthesis. In word-final and word-medial nonhomorganic conditions, the bilingual speakers' results are more similar to the corpora patterns in favor of vowel epenthesis, whereas the monolingual speakers chose vowel epenthesis at the chance level. 


\begin{tabular}{c|ccc}
\hline Phonological environments & Bilingual VE $\%$ & Corpora VE\% & Monolingual VE\% \\
\hline Word-final & $68 \%$ & $80 \%$ & $49 \%$ \\
Word-medial & $64 \%$ & $77 \%$ & $51 \%$ \\
Homorganic (prenasal vowel lax) & $38 \%$ & $0 \%$ & $29 \%$ \\
Homorganic (prenasal vowel long) & $19 \%$ & $100 \%$ & $24 \%$ \\
\hline
\end{tabular}

Table 4. Comparison of the vowel epenthesis rates among the bilingual/monolingual experimental results and the corpora data.

\section{Discussion and conclusion}

6.1 Discussion Other than faithful onset mapping, the adaptations of nasal consonants are contextualized. Miao (2005) shows that foreign nasals from Italian, German, and English are substituted by their corresponding nasals in SM, i.e. $/ \mathrm{m}, \mathrm{n}, \mathrm{y} /$. When necessary deviations occur, the only feature that is likely to show variability is place. Changeability is found in coda position due to SM phonotactic constraints. Lin (2011) also points out that although [n] is licit in coda position in SM, an English coda [n] sometime changes to [y] in SM loanwords. She claims that some features are better retained than others in the adaptation process and minimal deviation in some features is tolerated, suggesting that not all features are equally salient perceptually or of the same weight phonologically. Our study shows that although vowel epenthesis is the preferred syllable repair strategy in the corpora data, when deviations occur, the manner feature, [+nasal], is always preserved, whereas place feature may deviate. This indicates that the manner feature, [+nasal], is perceptually more salient than the place feature for nasal consonants.

The current study provides a detailed contextualized analysis and experimental evidence as well of how [m] is adapted into SM loanwords. We have demonstrated that consonant adaptation in SM loanwords is not always a faithful segment-to-segment matching process. Rather, as exemplified in this paper, the adaptation can be conditioned by phonetic and phonological factors related to the donor language and the recipient language and how the borrowers may have constructed the input for the final phase of the adaptation process. Specifically, we have shown that the phonological environments of [m] in English constitute the main condition that determines whether vowel epenthesis applies in SM loanwords, and suggested how the English inputs may have been perceived by SM speakers.

Given the overall similarity between the generalizations in the corpora data and the bilingual responses, we propose that for the bilinguals, vowel epenthesis is the preferred syllable repair strategy for segment/feature preservation (Paradis \& LaCharite 1997). Although the adapted form with vowel epenthesis is less phonetically similar to the English input regarding the number of syllables, the advantage of the vowel epenthesis strategy is that both nasality and labiality of [m] are preserved. On the other hand, the monolinguals tend to keep the perceptual similarity of syllable number between the input and the output by retaining nasal codas. Since the place contrasts in nasals are perceptually weak (Kawahara \& Garvey 2015), the match between coda $[\mathrm{m}]$ and coda $[\mathrm{n} / \mathrm{n}]$ is perceptually more similar than the match between a coda [m] and a syllable [mu:]. Therefore, vowel epenthesis is less preferred by the monolinguals.

Nasal place change is generally preferred in the homorganic condition so as to maintain perceptual similarity, since English [m.p]/[m.b]/[m.f] are produced with a gestural overlap (Henderson \& Repp 1982, Browman \& Goldstein 1990). However, unlike the patterns in the corpora, the bilingual and monolingual speakers do not prefer vowel epenthesis in the homorganic condition with a long vowel. This could be attributed to the fact that this specific set of data from the corpora is based on only two words. The experimental data of this study provides more information of how CVVm in English is adapted into SM loanwords; e.g., a long vowel or diphthong followed by a nasal in English can become short in SM. In fact, adaptation of English [au] to SM [a]/[a] is not rare at all. Usually, both diphthong and monothong forms appear in the SM loanwords, e.g. Downey $\rightarrow$ [tau.ni:] [ $\mathrm{t}^{\mathrm{h}}$ ay.ni:], and Downton $\rightarrow$ [tau.tun] [ $\mathrm{t}^{\mathrm{h}}$ ay.tun].

The results from the experiment also support Smith's (2006) and Davidson's (2007) claim that there is variability in auditory loanword adaptations, since perceptual cues are affected by the variable release of English coda consonants (Malécot 1958, Selkirk 1982, Crystal \& House 1988, Davidson 2011). This seems to suggest that phonological considerations other than necessary syllable repairs are suppressed in favor of perceptual similarity in the perceptual experimental setting. 
6.2 Conclusion Based on the corpora data, we have demonstrated that vowel epenthesis in SM loanwords is conditioned by the phonological environment of English coda [m], and proposed that vowel epenthesis is principally motivated by SM native phonology to fix the illicit coda. Vowel epenthesis is also likely to improve the perceived similarity between the English input and the SM loanword output in terms of any perceived release of $[\mathrm{m}]$. We conclude that using vowel epenthesis as the repair strategy can be attributed to the interaction between perception and SM syllable structure constraints. The bilingual experimental results show similar patterns in that vowel epenthesis appears when the $[\mathrm{m}]$ is in word-medial and word-final coda positions in English. Both bilingual and monolingual results indicate that vowel epenthesis is less preferred in general when the coda [m] is followed by a homorganic consonant in English. The bilingual results also support the claim that the existing loanwords are adapted by bilingual speakers who have access to the phonological categories and constraints of both the source and their native language (Paradis \& Tremblay 2009, LaCharité \& Paradis 2005), whereas monolingual speakers tend to rely more on perception during the adaptation process.

Besides the corpora data, this study provides new experimental evidence showing the similarities and differences between monolinguals and bilinguals in adapting loanwords, and suggests that the process of establishing loanwords requires both perceptual and phonological explanations (Chang 2008, Kang 2003, Kenstowicz \& Suchato 2006).

\section{Appendix}

The word list of the test items. (The outputs are shown in Pinyin, Chinese romanization, with tone number)

\begin{tabular}{|l|l|l|l|l|l|}
\hline Token & SM output A & SM output B & Token & SM output A & SM output B \\
\hline ['limdi] & li2 mu3 di2 & lin2 di2 & [lim] & lin2 & li2 mu3 \\
\hline ['lemdi] & lei2 mu3 di2 & lan2 di2 & [lem] & lei2en1 & lei2 mu3 \\
\hline ['lumdi] & lu3 mu3 di2 & lun2 di2 & {$[$ lum] } & lun2 & lu2 $\mathrm{mu} 3$ \\
\hline ['lomdi] & luo2 mu3 di2 & long2 di2 & {$[$ lom] } & long2 & lou2 mu2 \\
\hline ['limdi] & lin2 mu3 di2 & lin2 di2 & {$[\mathrm{lm}]$} & lin1 & lin2 mu3 \\
\hline ['lemdi] & lan2 mu3 di2 & lan2 di2 & {$[$ lem] } & lan2 & lan2 mu3 \\
\hline ['læmdi] & lan2 mu3 di2 & lan2 di2 & [læm] & lan2 & lan2 mu3 \\
\hline ['lomdi] & lun2 mu3 di2 & lun2 di2 & [lom] & lun2 & lun2 mu3 \\
\hline ['lomdi] & long2 mu3 di2 & long2 di2 & [lom] & long2 & long2 mu3 \\
\hline ['lamdi] & lang3 mu3 di2 & lang3 di2 & [lam] & lang4 & lang4 mu3 \\
\hline ['lidim] & li4 di2 mu3 & li4 ding3 & ['limbi] & lin2 bi3 & lin2 mu3 bi3 \\
\hline ['ledim] & lei2 di2 mu3 & lei2 ding3 & ['lembi] & lan2 bi3 & lan2 mu3 bi3 \\
\hline ['ludim] & lu4 di2 mu3 & lu4 ding3 & ['lumbi] & lun2 bi3 & lun2 mu3 bi3 \\
\hline ['lodim] & luo4 di2 mu3 & luo4 ding3 & ['lombi] & long2 bi3 & long2 mu3 bi3 \\
\hline ['lidim] & li4 di2 mu3 & li4 ding3 & ['limbi] & lin2 bi3 & lin2 mu3 bi3 \\
\hline ['ledim] & lei2 di2 mu3 & lei2 ding3 & ['lembi] & lan2 bi3 & lan2 mu3 bi3 \\
\hline ['lædim] & la1 di2 mu3 & la1 ding3 & ['læmbi] & lan2 bi3 & lan2 mu3 bi3 \\
\hline ['lodim] & lu4 di2 mu3 & lu4 ding3 & ['lombi] & lun2 bi3 & lun2 mu3 bi3 \\
\hline ['lodim] & luo4 di2 mu3 & luo4 ding3 & ['lombi] & long2 bi3 & long2 mu3 bi3 \\
\hline ['ladim] & la1 di2 mu3 & la1 ding3 & ['lambi] & lang3 bi3 & lang3 mu3 bi3 \\
\hline
\end{tabular}

\section{References}

Abaglo, P., \& Archangeli, D. (1989). Language-particular underspecification: Gengbe /e/ and Yoruba /i/. Linguistic Inquiry, 457-480.

Archangeli, D. (1988). Aspects of underspecification theory. Phonology, 5 (02), 183-207.

Boersma, P. \& Weenink, D. (2016). Praat: doing phonetics by computer [Computer program]. Version 6.0.15, retrieved 23 March 2016 from http://www.praat.org/.

Browman, C. P. \& Goldstein L. (1990). Tiers in articulatory phonology, with some implications for casual speech. In 
John Kingston \& Mary E. Beckman eds., The grammar and physics of speech, 341-376.

Chang, C. B. (2008, December). Phonetics vs. phonology in loanword adaptation: Revisiting the role of the bilingual. In Annual Meeting of the Berkeley Linguistics Society, 34 (1), 61-72.

Crystal, T. H., \& House, A. S. (1988). Proceedings of the Annual Meeting, Berkeley Linguistics Society 34. The duration of American-English stop consonants: an overview. Journal of Phonetics, 16. 285-294.

Davidson, L. (2007). The relationship between the perception of non-native phonotactics and loanword adaptation. Phonology, 24 (02), 261-286.

Davidson, L. (2011). Characteristics of stop releases in American English spontaneous speech. Speech Communication, $53(8), 1042-1058$.

Duanmu, S. (2000/2007). The phonology of standard Chinese. $1^{\text {st }}$ edn. $/ 2^{\text {nd }}$ edn. Oxford University Press.

Dupoux, E., Kakehi, K., Hirose, Y., Pallier, C., \& Mehler, J. (1999). Epenthetic vowels in Japanese: A perceptual illusion?. Journal of experimental psychology: human perception and performance, 25 (6), 1568-1578.

Google Maps. (2015). The United States of America and Canada.

Hall, N. (2006). Cross-linguistic patterns of vowel intrusion. Phonology, 23 (03), 387-429.

Henderson, J. B., \& Repp, B. H. (1982). Is a stop consonant released when followed by another stop consonant?. Phonetica, 39 (2-3), 71-82.

Hsieh, F. F., Kenstowicz, M., \& Mou, X. (2009). Mandarin adaptations of coda nasals in English loanwords. Calabrese \& Wetzels (2009), 131-154.

Hyman, L. (1970). The role of borrowing in the justification of phonological grammars. Studies in African linguistics, 1 (1), 1 .

Itô, J., Mester, A., \& Padgett, J. (1995). Licensing and underspecification in Optimality Theory. Linguistic inquiry, 571-613.

Kang, Y. (2003). Perceptual similarity in loanword adaptation: English postvocalic word-final stops in Korean. Phonology, 20 (2), 219-274.

Kang, Y. (2011). "Loanword phonology" In van Oostendorp, Marc, Colin Ewen, Elizabeth Hume, \& Keren Rice, eds., Companion to Phonology, 2258-2282. Wiley-Blackwell.

Katayama, M., (1998). Optimality Theory and Japanese Loanword Phonology (Doctoral dissertation). University of California at Santa Cruz.

Kawahara, S., \& Garvey, K. (2015). Nasal place assimilation and the perceptibility of place contrasts. Open Linguistics, 1 (1), 17-36.

Kenstowicz, M. (2003). Salience and Similarity in Loanword Adaptation: A Case Study from Fijian. Unpublished manuscript, Massachusetts Institute of Technology (ROA).

Kenstowicz, M., \& Suchato, A. (2006). Issues in loanword adaptation: A case study from Thai. Lingua, 116 (7), $921-$ 949.

Kim, K., \& Kochetov, A. (2011). Phonology and phonetics of epenthetic vowels in loanwords: Experimental evidence from Korean. Lingua, 121 (3), 511-532.

LaCharité, D., \& Paradis, C. (2005). Category preservation and proximity versus phonetic approximation in loanword adaptation. Linguistic inquiry, 36 (2), 223-258.

Lin, Y.-H. (2007). The Sounds of Chinese with Audio CD (Vol. 1). Cambridge University Press.

Lin, Y.-H. (2011). "Loanword adaptation in Standard Mandarin and phonological theory". In Xiao, Y., Tao, L., \& Soh, H. L, eds., Current issues in Chinese linguistics, 426-451. Cambridge Scholars Publishing.

Malécot, A. (1958). The Role of Releases in the Identification of Released Final Stops: A Series of Tape-Cutting Experiments. Language, 34 (3), 370-380. Linguistic Society of America.

Miao, R. (2005). Loanword adaptation in Mandarin Chinese: Perceptual, phonological and sociolinguistic factors (Doctoral dissertation). Stony Brook University.

Paradis, C. (1996). The inadequacy of filters and faithfulness in loanword adaptation. In Jacques Durand, \& Bernard Laks eds., Current trends in phonology: Models and methods. 509-534. Salford: University of Salford Publications. From http://www.fl.ulaval.ca/lii/caparadis/articles/Paradis_1996.pdf

Paradis, C., \& LaCharité, D. (1997). Preservation and minimality in loanword adaptation. Journal of linguistics, 33 (02), 379-430.

Paradis, C., \& Lacharité, D. (2011). "Loanword Adaptation: From lessons learned to findings". In John. Goldsmith, J. Riggle \& A. C. L. Yu, eds., The Handbook of Phonological Theory, Second Edition, 751-778. Wiley-Blackwell, 
Oxford, UK.

Paradis, C., \& Tremblay. A. (2009). "Nondistinctive features in loanword adaptation: The unimportance of English aspiration in mandarin Chinese phoneme categorization". In Andrea Calabrese \& W. Leo Wetzels, eds., Loan Phonology, 211-224. Amsterdam/Philadelphia: John Benjamins Publishing Company.

Park, W. (1987). Western loan-words in Japanese. Japanological Studies 5. University of Stockholm, Institute of Oriental Languages, Department of Japanese.

Peirce, J. W. (2009) Generating stimuli for neuroscience using PsychoPy. Front. Neuroinform. 2:10. doi:10.3389/neuro.11.010.2008

Peperkamp, S., Vendelin, I., \& Nakamura, K. (2008). On the perceptual origin of loanword adaptations: experimental evidence from Japanese. Phonology, 25 (01), 129-164.

Pulleyblank, D. (1988). Vocalic underspecification in Yoruba. Linguistic inquiry, 19 (2), 233-270.

Repetti, L. (2012). Consonant-final loanwords and epenthetic vowels in Italian. Catalan journal of linguistics, 11, $167-$ 188.

Rose, Y. (1995). Minimalité, pré servation et tolérance dans les emprunts franc ais en Kinyarwanda (M.A. thesis). Université Laval.

Selkirk, E. (1982). "Syllables”. In H. van der Hulst \& N. Smith, eds., The structure of phonological representations, 2 , 337-383. Foris Publications, Dordrecht, Holland.

Shinohara, S. (1997). Analyse phonologique de l'adaptation japonaise de mots étrangers (Doctoral dissertation). ANRT, Université de la Sorbonne Nouvelle, Paris, France.

Smith, J. L. (2006). Modeling loanword adaptation: Evidence from Japanese. In International Conference on East Asian Linguistics, University of Toronto.

Smith, N. (1977). Vowel epenthesis in the Surinam Creoles. Amsterdam Creole Studies 1, 1-54.

Steriade, D. (2008). "The phonology of perceptibility effects: The P-map and its consequences for constraint organization". In Kristin Hanson \& Sharon Inkelas, eds., The nature of the word, 151-179. Cambridge: MIT Press.

Uffmann, C. (2006). Epenthetic vowel quality in loanwords: Empirical and formal issues. Lingua, 116 (7), 1079-1111.

Uffmann, C. (2007). Vowel epenthesis in loanword adaptation (Vol. 510). Walter de Gruyter.

新英漢辭典 [A New English English-Chinese Dictionary]. 1988. Ed. By the editing group of a New English-Chinese Dictionary. Seattle: University of Washington Press. 